\title{
A ADOLESCÊNCIA COMO UM CONSTRUCTO SOCIAL*
}

\author{
ADOLESCENCE AS A SOCIAL CONSTRUCT
}

Maria Amélia de C. Oliveira ${ }^{1}$

Emiko Y. Egry ${ }^{2}$

OLIVEIRA, M. A. C.; EGRY, E. Y. A Adolescência Como Um Constructo Social. Rev. Bras. Cresc. Desenv. Hum., São Paulo, 7 (2), 1997.

Resumo: Na atualidade, questões ligadas à saúde dos adolescentes têm sido predominantemente interpretadas segundo o paradigma biomédico, que toma a adolescência um fenómeno natural, universal. Tal visão unívoca e a-histórica enfatiza o caráter teleológico do desenvolvimento hu nano, em que a adolescência não é mais que uma etapa de transição em direção à idade adulta, daí que privilegie o critério cronológico como seu principal demarcador. Advoga-se a sua compreensão como um constructo social, produto da Revolução Indushial, que adquire visibilidade ao final do século XIX, na esteira do movimento de proteção à maternidade e à infancia iniciados no século anterior. Admitir o caráter histórico-social do objeto adolescência implica pensá-la como um conceito necessariamente plural e em permanente evolução, atravessado por categorias como classe social, religião, raça e género, de tal forma que o adolescente genérico não seria mais que uma metáfora, um instrumento de inteligibilidade. $\mathrm{O}$ deslocamento da ênfase do substrato biológico para os múltiplos processos de sua construção, histórica, cultural e socialmente determinados, operaria a necessária subordinação da dimensão natural à dimensão histórica.

Palavras-chave: adolescência, adolescente.

\section{INTRODUÇAO}

A concepção predominante na atualidade, que identifica a adolescência como um fenômeno universal, resulta de uma visão unívoca e a-histórica dos adolescentes, definidos e identificados em função de seus atributos, com ênfase no caráter teleológico do desenvolvimento humano, que se completaria na idade adulta. A infancia e, especialmente, a adolescência não seriam mais que etapas nesse contínuo, fases de transição entre o organismo infantil, incompleto e inacabado, para o adulto, esse sim pronto, acabado e socialmente ajustado. Dessa forma, o critério cronológico é privilegiado para distinguir essa etapa evolutiva em direção à maturidade.

Assim sendo, o adolescente é definido por oposição à criança e ao adulto, por suas características e necessidades peculiares é mais que um, menos que o outro. Visto como um ser em transição, é de certo modo “desqualificado”, pois Ihe faltam as habilidades e competências do adulto.

* Originalmente parte de: Oliveira, M. A. C. A adolescência, o adolescer e o adolescente: re-significação a partir da determinação social do processo saúde-doença. São Paulo 1997, 142 p. Tese de Doutorado - Escola de Enfermagem da Universidade de São Paulo.

1 Profa. Dra. do Departamento de Enfermagem em Saúde Coletiva da Escola de Enfermagem da Universidade de São Paulo.

2 Profa. Tit. do Departamento de Enfermagem em Saúde Coletiva da Escola de Enfermagem da Universidade de São Paulo. End: Av. Dr. Enéas de Carvalho Aguiar, 419. São Paulo, SP - CEP: 05433-000. 
A adolescência é, assim, identificada com a puberdade, segundo uma matriz de interpretação que PERES (1995 p. 29 e 33) denominou de paradigma médico-biológico ou biomédico, em que “... as concepções sobre a adolescência partem do pressuposto de que se trata de um fenômeno natural, universal, subordinando os componentes psicológicos e sócio-culturais às transformações físicas geradas pela puberdade".

Verifica-se ainda o que AYRES (1990) denominou de binômio universalização-individuação, em que as categorias utilizadas para a identificação da condição individual são construídas a partir de uma concepção generalizante. Porque referida a um fenômeno físico, portanto natural, a adolescência assume um estatuto de fixidez e imutabilidade, com a naturalização de algo que foi produzido culturalmente.

No entender de PERES (1995, p. 33-4), mesmo a agregação de outros componentes ou atributos ao critério cronológico a fim de conseguir uma definição mais ampliada para o fenômeno da adolescência que permita distingüi-la da puberdade não logra superar o paradigma médico-biológico, “....visto tratarem o 'social'/'cultural' como simples atributo da adolescência/adolescente, não ultrapassando a lógica biológica em sua essência”.

Daí a dificuldade de estabelecer critérios precisos de de marcação para a adolescência, em decorrência de seus limites imprecisos que questionam a possibilidade de uma definição universal, genericamente aplicável a todos os adolescentes, independentemente do momento histórico e das sociedades de que façam parte.

A adoção de um determinado conceito, como uma elaboração intelectual articulada à realidade social em que se insere, implica muito mais que um simples enunciado, pois orienta as intervenções voltadas à transformação do objeto. Propõe-se aqui refazer o percurso histórico das práticas em saúde e a forma como recortam inicialmente o objeto infância e, posteriomente, a adolescência.

\section{AADOLESCÊNCIA COMO UM CONSTRUCTO SOCIAL}

Até o início do século XX, o desenvolvimento físico, emocional e cognitivo dos seres humanos era muito pouco conhecido. As crianças eram vistas como adultos em miniatura que, à medida em que cresciam, desenvolviam-se física e emocionalmente na mesma proporção. Para CAVALCANTI (1988), a adolescência é uma "invenção social” do século XVIII, produto da revo- lução industrial, assim como a infância o é da burguesia. Contribuíram para a sua visibilidade a instituição do sistema escolar obrigatório e os projetos de proteção à maternidade e à infância. ARIES (1981), entretanto, chega a afirmar que o seu reconhecimento como uma etapa peculiar da vida humana não ocorreu antes do final do século XIX.

Na segunda metade do século XVIII, a Revolução Industrial levara a profundas transformações econômicas e também a uma nova ética, fundada na insistência na ordem, na eficiência e na disciplina social e a uma preocupação com a condição humana. Na esfera da saúde, dentre os inúmeros movimentos que se sucederam, podem ser citados o da criação dos hospitais e dispensários e o movimento pelo bem-estar de mães e crianças (ROSEN, 1994).

Para ROCHA (1995), as origens do movimento de proteção à maternidade e à infância nas sociedades ocidentais datam do final do século XVIII, vinculadas ao ideário do Iluminismo, na sua busca do "aperfeiçoamento do ser humano", a ser obtido através da educação, da higiene e da ampliação de seus direitos sociais, incluindo-se aí a proteção à saúde.

O humanitarismo Luminista, entretanto, em geral subestimava a dimensão econômica envolvida em seu projeto emancipador e a difusão do conhecimento visava as classes mais favorecidas. Havia a crença na "inevitabilidade do progresso e esperança na salvação humana baseada em uma revolução da moralidade social e o desejo de persuadir os outros da necessidade e racionalidade dessa mudança” (ROSEN,1994, p. 147).

Essas idéias se faziam presentes nos discursos dos filósofos da época, como os franceses Diderot, d'Alembert, Voltaire e Rousseau. Diderot (1713-84), em um artigo intitulado "O Ser humano" discutiu o impacto da mortalidade infantil sobre o tamanho das populações, instando que fossem tomadas medidas para a sua redução (ROSEN, 1994). A estreita vinculação que as questões da maternidade e da infância guardam, desde o seu inicio, com o "problema populacional” levou Marques (s/d apud ROCHA, 1995, p. 3) a afirmar que: “...o projeto internacional desencadeado há pelo menos três séculos, denominado movimento pelo bem-estar da maternidade e da infância ou movimento de proteção à maternidade e à infância, tem implícita a intenção de controlar medicamente o crescimento excessivo ou o declínio do tamanho da população de uma determinada nação, associado à idéia de que isto se faz garantindo uma proteção especial à saúde das crianças e das mães.”

As primeiras medidas voltaram-se para as crianças pobres e abandonadas, mas também nesse 
século criaram-se os serviços de saúde destinados àquelas em idade escolar. Tais medidas foram precedidas por uma considerável expansão populacional iniciada por volta de 1750 , com o conseqüente aumento do número de crianças, especialmente aquelas oriundas das classes mais pobres, o que também elevou os índices de mortalidade infantil (ROSEN,1994).

Havia também crescido o número de crianças ilegítimas, freqüentemente deixadas à própria sorte, quando não assassinadas, o que motivou a criação em 1741 do Hospital de Enjeitados de Londres. Também na Inglaterra, em 1748, William Cadogan fez publicar o seu "Um ensaio sobre a amamentação e o manejo de crianças", defendendo o direito da criança à vida e à liberdade $\mathrm{e}$ propondo algumas regras para a sua criação. Em 1769 foi criado o primeiro dispensário inglês para crianças pobres (ROSEN,1994).

Quase meio século após, em 1817, John Bunnell Davis, médico inglês, publicou um estudo intitulado "Uma investigação rápida sobre algumas das principais causas de mortalidade de crianças, com intenção de ajudar a melhorar o estado da geração crescente quanto à saúde, moralidade e felicidade" com base na sua atuação no dispensário para crianças que havia aberto um ano antes. Havia ainda redigido panfletos sobre a saúde da criança que eram distribuídos nas casas por uma equipe de visitadores por ele treinados para orientar as mães. ROSEN (1994, p. 272) considera que a obra de Davis tenha representado "uma fase de transição no desenvolvimento da Higiene Infantil moderna e da Enfermagem de Saúde Pública”.

Em 1834, um Ato de Emenda reformou a Lei dos Pobres ${ }^{3}$ inglesa lastreada nas posições teóricas da doutrina da necessidade filosófica, da economia política de Smith, Malthus e Ricardo dos Filósofos Radicais. Tais posições contrapunham-se a medidas assistencialistas voltadas para os pobres, advogando a neutralidade do Governo frente à pobreza, que seria solucionada pelo próprio progresso, que também levaria ao aumento da educação e ao aperfeiçoamento moral. A economia política tinha “o empreendimento privado como fonte principal do progresso social” e os filósofos radicais, que tinham em Benthan seu maior expoente, propunham a utilização da racionalidade científica para lidar com os problemas sociais (ROSEN, 1994, p. 159-61).
Discípulo de Benthan, Edwin Chadwick foi o relator indicado pela Comissão Real para examinar como a Lei dos Pobres estava sendo posta em prática. As recomendações contidas em seu relatório foram incorporadas ao Ato de Emenda e, assim, restringiu-se a assistência aos fisicamente incapazes e aos miseráveis. Entretanto, foi mérito de Chadwick conseguir o reconhecimento público dos custos econômicos e sociais das doenças evitáveis, favorecendo o desenvolvimento de ações que visassem à melhoria da saúde da população. Suas propostas, que a partir de então, vieram a influenciar profundamente a Saúde Pública inglesa, voltavam-se mais para o ambiente, de modo que o equacionamento dos problemas de saúde passou a ser considerado mais tarefa da Engenharia que da própria Medicina (ROSEN,1994).

Na Alemanha do século XVIII, a preocupação com a política populacional havia levado Johann Peter Frank, legítimo representante da Polícia Médica alemã, a abordar a saúde da criança no segundo livro do conjunto de seis volumes que escrevera (o primeiro publicado em 1779 e o último em 1817), incluindo a saúde escolar e a supervisão médica de instituições educacionais (ROSEN,1994).

Inspirado em Frank, Frans Anton Mai, em seu Código de Saúde, 1800, preconizou a educação em saúde como um instrumento que deveria ser utilizado junto a crianças e professores para manter e promover a saúde, inclusive com esclarecimentos aos adolescentes, alertando-os sobre os perigos dos “excessos sexuais” (ROSEN,1994, p. 136).

Na França, à semelhança do que acontecia em solo inglês, a preocupação com a criança traduziu-se na publicação de algumas obras em meados do século XVIII, como é o caso de “A ortopedia ou a arte de prevenir e corrigir nas crianças as deformidades do corpo", de autoria de Nicholas Andery, que veio a público em 1741. Da mesma forma, o "Tratado de educação corporal na irzfancia ou reflexões práticas sobre os meios de procurar uma melhor constituição para os cidadãos”, de Jean-Charles des Essartz, datado de 1760. Nenhuma delas entretendo, repercutiu tanto nas concepções sobre a infância como "Emile", de Jean-Jacques Rouseau, editada em 1762 (ROSEN,1994).

Em 1860, Alfred Caron fez publicar “A puericultura ou a ciência de criar os filho de um modo

3 Lei dos Pobres: sistema de assistência inglês que, desenvolvido no século XVI, perdurou até a 2a Guerra. As primeiras leis foram codificadas em 1597 e entraram em vigor em 1601, o Estado assumindo a assistência à pobreza, tarefa antes a cargo a igreja. 
higiênico e filosófico”, estabelecendo um programa especial de higiene para os lactentes e crianças sadias, a que denominou: puericultura. Seguido por inúmeros avanços na investigação da fisiologia e patologia das crian ças, tanto na França como na Alemanha e, mais tarde, também na Inglaterra e nos Estados Unidos, contribuiu para a constituição de uma nova especialidade, a pediatria (ROSEN, 1994). Em seu livro "Notas sobre enfermagem", publicado em 1859, juntamente com "Notas sobre hospitais”, Florence Nightingal, lançou os fundamentos da enfermagem pediátrica, embasandose na puericultura. Em um capítulo específico acrescentado à edição dá 1861, intitulado “Atendimento à criança”, Florence enumerou cuidados que deviam ser dispensados às crianças sadias em seus domicílios, relativos à alimentação, recreação, higiene pessoal e do ambiente. Tais normas e regras gerais evidenciam que a assistência à criança foi por ela apreendida em sua dimensão coletiva (ROCHA, 1990).

Em 1878, Friederich Ahlfeld, de Leipzig. começou a pesar os bebês - uma das maiores preocupaçõess dos pediatras do período era com a alimentação do recém-nascido. Em 1859 a Enfermaria para Mulheres e Crianças de Nova York nomeou uma visitadora para realizar visitas domiciliárias a fim de instruir as mães sobre o cuidado às crianças, esforço que, em seguida, arrefeceu em virtude da Guerra Civil Americana (ROCHA, 1990).

Para ROCHA (1995, p. 3), a Pediatria surgiu no século XVIII imbuida de um projeto dá assistência social, de tal forma que a puericultura "é uma proposta disciplinadora de acompa nhamento do crescimento e desenvolvimento infantil, através de medidas de higiene corporal, alimentar e do ambiente, do nascimento à idade adulta, de forma normal e saudável. "Visava tanto a “infância em perigo” como a "infância delinqüente”, atuando para a manutenção da ordem social vigente, através da diminuição da tensão e das desigualdades sociais.

Segundo Rosen, "o início do movimento pela saúde da mãe e da criança tem raízes fundas nos abusos da industrialização dos primeiros anos deste século”. O movimento de proteção à saúde materno-infantil também guarda correspondência com a evolução de serviços voltados para o atendimento das crianças em idade escolar. O princípio das inspeções médicas em escolas data da Convenção de 1793 na França, porém apenas em 1842 o governo francês decretou que fossem feitas rotineirarnente, o que só veio a ocorrer de fato em 1879 (ROSEN, 1994).

Na Inglaterra, a Associação dos Médicos Escolares foi fundada em 1884 e os primeiros ser- viços de saúde voltados aos adolescentes foram organizados em escolas masculinas (SILBER, 1995).

Na Alemanha, os achados do estudo do oculista alemão Hermann Breslau, sobre a condições da visão de escolares, realizado em 1866, desencadeou inspeções sanitárias dos prédios escolares e a instauração de medidas para a prevenção das doenças transmissíveis (ROSEN, 1994).

Nos Estados Unidos, em 1902, empregouse pela primeira vez em tempo integral, uma enfermeira sanitarista para desenvolver atividades educacionais em uma escola de Nova York também visando ao controle das doenças transmissíveis. Em 1908, na mesma cidade, instituiu-se o programa de merenda escolar para suplementar a dieta de crianças mal nutridas, condição que fora denunciada, em 1906 no livro de John Spargo, “O grito amargo das crianças.” Esse programa foi extensivarnente implementado durante a depressão econômica dos anos 30 (ROSEN, 1994).

Estreitamente ligada aos programas materno-infantil e de saúde escolar estava a proposta da Educação em Saúde. Em 1919, o termo foi utilizado, pela primeira vez em uma conferência da Organização de Saúde da Criança que, em 1922, fundiu-se com a Associação Americana de Higiene da Criança, formando, assim, a Associação Americana de Saúde da Criança. (ROSEN, 1994).

No alvorecer do século XX, constatou-se que o liberalismo econômico falhara em cumprir suas promessas. Não só o avanço industrial mostrava-se incapaz de eliminar a pobreza, como haviam se agravado as condições de vida dos pobres. Desencadearam-se, assim, projetos reformistas na Europa e nas Américas pleiteando a participação do Estado na regulação das condições de vida e saúde das populações (ROSEN, 1994).

O decréscimo no número de nascimentos e a consciência de que muitas vidas estavam sendo ceifadas coincidem com o reaparecimento das idéias mercantilistas de conquistar colônias e de mercados em expansão. Por essa razão, “a preocupação com todas as fases da vida infantil se mostrou uma característica eminente do movimento por melhorias sociais...” em que a ênfase recaía sobre "as condições de higiene geral para a prevenção das doenças, aperfeiçoamento da dieta e cuidados pré-natais” (ROSEN, 1994).

\section{A VISIBILIDADE SOCIAL DA ADOLESCÊNCIA}

Os programas materno-infantis da primeira década deste século tinham, em comum, ensi- 
nar as mães a criar seus filhos, a construção de clínicas especializadas e a provisão de leite saudável para as crianças, ao mesmo tempo em que se organizavam os serviços voltados para a dispensação de cuidados pré-natais (ROSEN, 1994).

Nessa época começam a surgir os primeiros estudos dedicados aos adolescentes. Em 1904, o psicólogo Stanley Hal1 publicou sua obra em três volumes intitulada "A adolescência: sua psicologia, sua relação com a filosofia, sociologia, sexo, crime, religião e educação”. Um ano depois, Freud publicaria "Três ensaios sobre a teoria da sexualidade”, em que se refere à tarefa específica de atingir uma sexualidade madura, situando-a no contexto da puberdade, sem no entanto fazer referência à adolescência (RAKOFF, 1995).

A primeira publicação médica é de 1918: "O trabalho da clinica de adolescentes da Faculdade de Medicina da Universidade de Stanford”, de Amália Gates, enumerando os principais problemas de saúde dos adolescentes, que haviam sido atendidos naquela instituição (SILBER, 1995).

Nas décadas de 20 e 30, inúmeros grupos médicos dedicaram-se ao estudo do desenvolvimento biológico e da nutrição de adolescentes, dentre os quais SILBER (1995) destaca a Unidade de Estudo do Adolescente da Universidade de Yale, integrada por pesquisadores das áreas de anatomia, fisiologia, bioquímica, pediatria e psicologia, que investigaram a endocrinologia da puberdade, a idade óssea e as modificações corporais na adolescência.

Estudos realizados em Viena sobre os caracteres sexuais secundários dos adolescentes culminaram com a publicação de "Estudos somáticos e endocrinológicos do varão púbere”, de Greulich e colaboradores. Essa era dos "precursores” encerrou-se com Tanner e a sistemática de avaliação da maturação sexual, publicada no seu livro "Crescimento na adolescência” (SILBER, 1995).

Após a II Guerra Mundial, quando os principais problemas relacionados às doenças transmissíveis haviam sido controlados, os conhecimentos produzidos sobre a biologia da puberdade e as transformações demográficas havidas tornaram mais visível esse grupo populacional.

Em 1951, Gallager criou o primeiro Programa de Medicina da Adolescência em Boston, à mesma época em que a médica Gomes Ferrarotti criava o Centro Municipal da Adolescência em Buenos Aires, Argentina e Paula Peláez, o Consultório de Adolescentes em Santiago, Chile. Estes foram seguidas por outros serviços pioneiros na América Latina, como os chefiados por Anita Colli, em São Paulo, Maria Helena Ruzany, no Rio de Janeiro, e o de Enrique Gutierrez, no México (SILBER, 1995).

Em 1960, Gallager publicou "A atenção médica ao adolescente” apresentando os resultados obtidos ao longo da década anterior em seu serviço. Em 1968, foi criada, nos Estados Unidos, a Sociedade de Medicina do Adolescente e o boletim informativo, por ela editado, transformouse, em 1980, no "Journal of Adolescent Health Care” (SILBER, 1995).

Frente à relevância alcançada pelas questões relativas à adolescência, a OMS realizou uma primeira reunião de especialistas em 1977, o que resultou na publicação de informes técnicos sobre os problemas e necessidades de saúde dos adolescentes. Em seguida, a Academia Norte-americana de Pediatria criou a Seção de Adolescência. Em 1976, havia sido publicado o primeiro Documento sobre Saúde dos Adolescentes na Região das Américas e, em 1977, a Associação Médica Norte-americana reconheceu a Hebeatria como especialidade, à semelhança do que já fizera a Associação Médica Argentina (SILBER, 1995).

Os precursores da teoria psicodinâmica da adolescência foram Stanley Hall e Freud. Com Freud, questões da luta ético-moral foram transformadas em problemas médicos, passíveis de intervenção terapêutica. RAKOFF (1995) afirma que o modelo psicológico freudiano de ser humano foi um produto de sua época, fruto de estruturas intelectuais herdadas do século precedente. $\mathrm{O}$ pensamento europeu achava-se profundante impregnado pela dialética hegeliana que, por sua vez, era produto e reflexo das forças sócio-políticas que haviam surgido da Revolução Francesa e da Guerra da Independência norte-americana” ... Era como si el reto lanzado a las verdades establecidas y eternas, el énfasis sociopolítico en los derechos dei individuo y las luchas individuales, la afirmación burguesa dei derecho y la capacidad empresarial de la persona se reflexaran en una desviación de locus de las inquietudes psicológicas de lo 'objetivamente moral' a lo subjetivo. La subjetividad se convertia en una espécie de causa filosófica” (RAKOFF, 1995).

Em 1964, Erikson publicou "Infância e sociedade", em que afirmava que a tarefa principal do adolescente é o estabelecimento de uma identidade segura. Ao final do século XX, a terminologia por ele utilizada havia se disseminado amplamente, como é o caso dos termos “alienação" e "anomia”, que utilizara para designar os componentes econômicos e sociais da incoerência e da insensatez que dizia serem subjacentes à perda da identidade (RAKOFF, 1995). 
Em 1966, Anna Freud trouxe a público o postulado da normalidade da turbulência do adolescente em "O ego e 05 mecanismos de defesa", afirmando que o estado previsível para um determinado adolescente é uma turbulência episódica, associada a seus sentimentos de culpa por ter fantasias proibidas, aos seus anseios frustrados por maior autonomia e independência e às suas dúvidas e incertezas sobre quem é e sobre o que dele se espera. Um ano depois, Blos publicou "O segundo processo de individuação da adolescência", postulando que a fase final da adolescência tem a ver com a separação e a individuação (NOSHPITZ, 1995).

Para REIS (1993), "a adolescência - conceito, na sua essência, histórico-antropológico, constituir-se-á em tema predileto da ciência psicológica da qual é, aliás, contemporânea”. ROJAS (1995) associa a imagem de adolescência que surge na literatura psicanalítica às transforrnações oriundas da Revolução Industrial: a industrialização, a urbanização, a racionalização e a burocratização. Para MONROY (1995), os postulados de Freud e Stanley Hall de que certas pautas do desenvolvimento e da conduta humana são unidades inseparáveis de sua natureza deram origem ao determinismo social e ao universalismo genético presentes na concepção atual de adolescência.

\section{CONSIDERA COES FINAIS}

A adolescência "inventada" pelo Ocidente caracteriza-se por sua longa duracão por sua indeterminação - dada por critérios de demarcação pouco fixos, pela carga de conflitos a ela associados e pela assincronia entre a maturação sexual e a conquista do status social de adulto, ou seja, assincronia entre o tempo biológico e o tempo social. Trata-se de um conceito que se erige sobre a base biológica da puberdade, mas a transcende, pois que a "cultura modula o biológico de um modo especificamente humano" (ROJAS, 1995). Dizer que se trata de um fenômeno cultural não equivale dizer que é arbitrário, já que referido a etapas cruciais do crescimento e desenvolvimento humanos. A idade, tal como o sexo, serve como substrato para a definição das características culturais e sociais dos seres humanos.

O conceito de adolescente é ensinado à criança no processo de socialização, daí que os fenômenos a ele ligados, tais como a duração, os comportamentos característicos, as formas de articulação com a família e outras organizações, são social e culturalmente determinadas. $\mathrm{O}$ mundo do adolescente é construído por adultos, que detém o poder necessário para construir o mundo e os recursos econômicos para fazê-lo. Por essa razão, a conformidade com o padrão "adulto", culturalmente aceitável constitui-se em um demarcador do final da adolescência (ROJAS, 1995).

A compreensão da adolescência como um momento de especial vulnerabilidade no desenvolvimento humano, associa-se ao conceito de risco, ainda que se trate de uma dada ordem de vulnerabilidade, pois que o adolescente é menos sujeito a agravos orgânicos que os demais grupos geracionais. Contraditoriamente, o risco é quase sempre reduzido à sua dimensão biológica, quando não ao “desajustamento" social. Assim, freqüentemente a adolescência é tida como um período conturbado, problemático, um momento crítico no trajeto evolutivo do ser humano em direção à idade adulta, perspectiva que toma corpo no conceito psicológico de crise que, por sua vez, lastreia-se na concepção psicossocial advogada por ABERASTURY \& KNOBEL (1981).

Já a compreensão da adolescência como uma construção histórico-social implica pensá-la como um conceito necessariamente plural, de tal forma que diferentes sociedades teriam conceitos diferentes e que, mesmo em uma dada sociedade, em um determinado momento histórico, haveria concepções diferenciadas de adolescente - segundo a classe social, a religião, a etnia, o gênero concepções essas em permanente transformação (LOURO,1996). Implicaria, portanto, no deslocamento da ênfase da sua “essência”, do substrato comum, natural, que a tornaria uma definição universal, para os múltiplos processos de sua construção, histórica, linguística e socialmente determinados, pois que: “As categorias raça, género e geração têm em comum serem atributos naturais com significados políticos, culturais e econômicos, organizados por hierarquias, privilégios e desigualdades, amparados por símbolos particulares e naturalizados. (...) A combinação de categorias é de fácil comprovação, já seu produto leva a outros resultados e o seu conhecimento exige saber que se inicia por ruptura com os esquemas duais" (CASTRO, 1992).

Submeter a dimensão natural à dimensãc histórica inverte a perspectiva dominante e permite distinguir o processo da história social do processo de evolução natural. Quando falamos em seres humanos, certamente falamos da história natural da espécie, já que somos feitos dá mesma matéria e estamos submetidos às leis da natureza que toma o tempo cronológico como referência. Mas é no tempo histórico que nos fazemos genuinamente humanos, "no tempo, denso, de criação, em que somos responsáveis pelo que somos", em que nos constituímos como seres históricos con- 
cretos, através de nossa intervenção intencional sobre a natureza ${ }^{4}$.

O adolescente genérico não seria, então. mais que "um macro-sujeito, um instrumento de inteligibilidade, de processos coletivos da construção humana da vida" (AYRES, 1994). Haveria, pois, que tomar os adolescentes como sujeitos concretos dos processos de intervenção a eles destinados, através de um “diálogo simétrico”, livre de opressão, capaz de fazer emergir suas "necessidades emancipatórias”; “Auscultar outras ne- cessidades dos adolescentes [que não apenas as orgânicas] em seus processos concretos de individuação/socialização é uma tarefa imprescindível para a organização de programas de saúde para o grupo. E essa ausculta que permite detectar demandas por informação, por espaços e por temas de discussão e reflexão, por oportunidades de experimentar-se, por apoio para aventurar-se, por subsídios para defender-se contra opressões de ordem social, política, econômica etc.” (AYRES \& FRANÇA JR., 1996, p.71).

\begin{abstract}
At the present time, issues linked to adolescents' health have been predominantly interpreted according to the biomedical paradigm, which takes adolescence as a natural and universal phenomenon. Such unidirectional and non-historical vision emphasizes the teleological character of human development, in which adolescence is not more than a transition stage towards adult age, thus privileging the chronological approach as its main milestone. We suggest the understanding of adolescence as a social construct, product of the Industrial Revolution, that acquires visibility at the end of the $\wedge 19 \sim \wedge$ h century, in the wake of the protection movement to maternity and childhood that had begun in the previous century. To admit the historical-social character of the object adolescence implies taking it necessarily as a plural concept, in permanent evolution, crossed by categories as social class, religion, race and gender, in such a way that the generic adolescent would not be more than a metaphor, an instrument of inteligibility. The displacement of the emphasis in the biological substratum for the multiple processes of its construction, historical, cultural and socially determined, would operate the necessary subordination of the natural dimension to the historical one.
\end{abstract}

Key-words: adolescence, adolescent.

\section{REFERÊNCIAS BIBLIOGRÁFICAS}

ABERASTURY, A.; KNOBEL, M. A adolescência normal. Porto Alegre, Artes Médicas, 1981.

ARIES, P. História social da criança e da família. Rio de Janeiro, Guanabara-Koogan, 1981.

AYRES, J. R. d. C. M. Adolescência e saúde coletiva: aspectos epistemológicos da abordagem programática. In: SCHRAIBER, L. B. (org.). Programação em saúde hoje. São Paulo, Hucitec, 1990. Cap.4: p. 139-82.

AYRES, J. R. d. C. M. Ação programática e renovação das práticas médico-sanitárias: saúde e emancipação na adolescência. Saúde Deb., 42: 54-8, 1994.

AYRES, J. R. d. C. M.; FRANÇA JUNIOR, I. Saúde do adolescente. In: SCHRAIBER, L.B. et al. (org.). Saúde do Adulto: programas e ações na unidade Básica. São Paulo, Hucitec, 1996. p. 66-85.

CASTRO, M. C. Alquimia de categorias sociais na produção dos sujeitos políticos. Estudos Feminiistas, 0/92: 57-73, 1992.
CAVALCANTI, R. C. Adolescência. In: VITELLO, N. et al. Adolescência hoje. São Paulo, Roca, 1988. p. 5-27.

CRESPIN, J. Trinta e cinco anos de medicina do adolescente no Brasil: o que mudou? Bol. Assoc. Bras. Adoiescência, 16: (4), 1996.

LOURO, G. L. Nas redes do conceito de gênero. In: LOPES, M. J. et al. Gênero e saúde. Porto Alegre, Artes Médicas, 1996. p.7- 18.

MONROY, A. Pubertad, adolescencia y cultura juve nil. In: MADDALENO, M. et al. La salud del adolescente e del joven. Washington, Organizació Panamericana de la Salud, 1995. p. 27-35 (Publicación científica n.552).

NOSHPITZ, J. D. El desarrollo psicosocial del adolescente. In: MADDALENO, M. et al. La salud do adolescente e del joven. Washington, Organizació Panamericana de la Salud. 1995. p. 95-111 (Publicación científican.552).

PERES, F. Adolescência: em busca dos sujeitos sociais São Paulo, 1995. [Tese de Doutorado Faculdade d Saúde Pública da Universidade de São Paulo].

4 De acordo com SEVERINO, A. J. "Desenvolvimento histórico da Educação, situação atual e perspectivas”. Aula proferida em 17 de março de 1998 na Escola de Enfermagem da USP como parte da disciplina Temas de Investigação em Saúde Coletiva do Curso de Pos-graduação em nível de mestrado - área de concentração Saúde Coletiva. 
RAKOFF, V. M. Una interpretación psicohistórica del adolescente. In: MADDALENO, M. et al. La salud, del adolescente e del joven. Washington Organización Panamericana de la Salud, 1995, p. 57-64. (Publicación científica n. 552).

REIS, A. O. A. O discurso da saúde pública sobre adolescente grávida: avatares. São Paulo, 1997 [Tese de Doutorado - Faculdade de Saúde Pública da Universidade de São Paulo].

ROCHA, S. M. M. O processo de trabalho em saúde e enfermagem pediátrica: socialidade e historicidade do conhecimento. Ribeirão Preto, 1990. [Tese d Livre-Docência - Escola de Enfermagem de Ribei rão Preto da Universidade de São Paulo].

ROCHA, S. M. M. A criança na sociedade brasileira educar, prevenir, cuidar. In: Congresso
Paulista $\mathrm{d} \wedge \mathrm{f}$ Enfermagem Pediátrica, l, São Paulo, 1995. Anai São Paulo, 1995. p.3-7.

ROJAS, D. S. Adolescência, cultura y salud. In: MADDALENO, M. et al. La salud del adolescente e del joven. Washington, Organización Panamericana de la Salud, 1995, p. 15-26. (Publicación científica n. 552).

ROSEN, G. Uma história da saúde pública. São Paulo/Rio de Janeiro, Hucitec-UNESPABRASCO, 1994.

SILBER, T. J. Medicina de la adolescência: su historia, crescimiento y evolución. In: MADDALENO, M. et al. La salud dei adolescente e dei jovem Washington, Organización Panamericana de la Salud, 1995. p. 65-9. (Publicación científica n. 552). 